\title{
Influence of Professional Learning on Elementary Teacher Self-Efficacy in Teaching with an Integrated STEM Approach
}

\author{
Ty Arendall ${ }^{1}$, Thomas Casteel $^{1}$, Brad Lewis ${ }^{1}$, Jodi Newton ${ }^{1, *}$, Leslie S. Ennis ${ }^{1} \&$ Karen \\ Birkenfeld $^{1}$
}

${ }^{1}$ Department of Educational Leadership, Samford University, 800 Lakeshore Drive, Birmingham, AL 35229, USA. Tel: 1-205-726-4240 E-mail: jbnewton@ samford.edu

Received: February 20, 2018

Accepted: March 13, 2018 Published: March 22, 2018

doi:10.5296/ije.v10i1.12687

URL: https://doi.org/10.5296/ije.v10i1.12687

\begin{abstract}
The purpose of the qualitative study was to determine the influence of key features of professional learning on teacher efficacy/attitudes towards Science Technology Engineering and Math (STEM) instruction. The study utilized a purposeful sampling of elementary teachers with a minimum of three years of experience in teaching STEM. The seven teachers selected for the study were from three school districts recognized for strong STEM programs, and they were identified by gatekeepers in those districts as highly confident and effective teachers of STEM. Rather than seeking to identify specific professional development models, the researchers sought a broader understanding of professional learning -specifically seeking to identify learning features that contributed to teacher self-efficacy in STEM. Data collected from structured interviews were analyzed using qualitative methods to answer research questions and determine a grounded theory. The data suggest that the following aspects of professional learning enhanced participants' self-efficacy to teach STEM: a) student focus, b) STEM learning continuum, c) networking, d) expertise, and e) culture. In addition, the researchers determined that the five core features of teacher professional learning first described by Desimone (2009) were present in the data: a) content focus, b) active learning, c) coherence, d) duration, e) collective participation. The researchers conclude by offering practical recommendations for educators seeking to implement STEM, as well as suggestions for future research studies.
\end{abstract}

Keywords: STEM, professional learning, teacher efficacy, student focus, networking 


\section{Research}

Research indicates that teachers are a primary determining factor in the effectiveness of Science Technology Engineering and Math (STEM) instruction; however, most teachers are not prepared to facilitate student learning using an integrated STEM approach (Nadelson, Callahan, Pyke, Hay, Dance, \& Pfeister, 2013). According to a White House Report "the most important factor in ensuring excellence is great STEM teachers, with both deep content knowledge in STEM subjects and mastery of the pedagogical skills required to teach these subjects well" (President's Council of Advisors on Science and Technology, 2010, p.xi). While teachers are the key to STEM instruction, teachers may feel less comfortable teaching STEM than other subjects (Yager, 2015). Robert Yager (2015) states "most science teachers have never experienced real science" (p. 211).

Integrated STEM teaching and learning has gained attention as schools prepare students for $21^{\text {st }}$ century learning careers. STEM has become "the mantra of the science education community and policymakers" and the "gold standard" in the field (Lederman \& Lederman, 2013, p. 1237). Research studies find that elementary students benefit from participation in science instruction that allows them to explore the natural world through inquiry using an approach that integrates various pedagogical content areas (DeJarnette, 2012). The widespread adoption of reforms in science education, based on recommendations from reputable professional organizations, creates expectations that students will engage in scientific practices in the classroom rather than hearing about those practices from their teachers secondhand (Yager, 2015).

A National Science Teachers Association (2002) position statement declares, "young children develop science understanding best when given multiple opportunities to engage in science exploration and experiences through inquiry" (p. 2). The concept of STEM was conceived in response to alarming trends that showed the United States and other western nations falling far behind other developed nations - particularly those in Asia (Blackley \& Howell, 2015). U. S. students continue to underperform in math and science despite the fact that U. S. outspends other nations in education (Organization for Economic Cooperation and Development, 2012). Among 36 Organization for Economic Cooperation and Development (OECD) nations, 15 year olds from the U. S. performed below average in math and science on the most recent 2012 Program for International Student Assessment (PISA), earning a ranking of $36^{\text {th }}$ in math and $20^{\text {th }}$ in science (OECD, 2012).

With U.S. students underperforming on international assessments, a sense of urgency to improve in STEM fields was felt immediately, but there was little agreement about the specific actions needed to improve STEM instruction in K-12 (Blackley \& Howell, 2015). As the recommendations of Next Generation Science Standards (NGSS Lead States, 2013) were widely adopted by states, key principles of the STEM philosophy found their way into instructional standards and state courses of study (Blackley \& Howell, 2015). The benefits to student learning of an integrated STEM approach were widely accepted, but many teachers continued to teach using traditional disciplines, techniques, and resources (Herschbach, 2011). With the adoption of the Next Generation Science Standards (NGSS Lead States, 2013) in 
course of study standards, teachers of science are essentially mandated to utilize an integrated, inquiry-based approach. Research indicates that effective professional learning for teachers results in increased teacher confidence and provide positive benefits to student learning (Maltese \& Tai, 2010, Nadleson, et al., 2013).

Given that many elementary teachers lack the training, confidence, knowledge, and pedagogical strategies to effectively facilitate the learning of their students using an integrated STEM approach, a variety of efforts have been implemented to give educators the support they need to be effective facilitators of student learning in STEM (Nadelson et al., 2013; Nadelson, 2015). Efforts focused on providing teachers with more STEM training through pre-service preparation programs or professional development for practicing teachers have demonstrated mixed results (Kim, Kim, Yuan, Hill, Doshi, and Thai, 2015; van Driel et al., 2001). Efforts to create partnerships between STEM experts and K-12 educators did not represent a viable solution to the STEM problem because many K-12 schools do not have access to these resources (Lehman, Kim, \& Harris 2014; Bissaker, 2014, Galluci, 2008). Other researchers have utilized instructional models and tools such as rubrics, lesson templates, and learning frameworks to provide additional support to teachers (Nadelson, 2015).

Nadelson et al. (2013) noted that even when targeted professional development resulted in significant increases in teacher knowledge about STEM, delayed post-tests revealed that impacts on student learning were not significant. Increased teacher learning did not transfer to significant increases in learning in the classroom. Nadelson et al. (2015) concluded that additional reinforcement in professional development might result in greater impact on student learning (p. 38). van Driel, Beijaard, and Verloop (2001) found that while traditional short-term professional development programs increased teacher science knowledge; when implementing an innovation, "problems were reported in all studies" (p. 148).

Without provisions for additional sustained reinforcement at the school level, it is unlikely that STEM professional learning effects will prove lasting or significantly impact student learning (van Driel, et al. 2001). Mobley (2015) concluded that the complexities of STEM integration meant that professional learning could not be sporadic or piecemeal, but required frequent and repeated reinforcement. Teacher interviews conducted as a part of Mobley's (2015) mixed methodology study of teacher self-efficacy in teaching STEM revealed that nearly all participants expressed a desire for additional collaboration among their teaching peers. Galosy and Gillespie (2013) found that teachers required support in three mutually reinforcing areas: (1) content-rich professional community, (2) collective inquiry into practice, and (3) leadership from the classroom. Ensuring teachers have access and time to collaborate together was predicted to positively influence gains in teacher confidence in their abilities.

Like STEM, the concept of teacher professional learning has evolved over time. Effective professional learning for teachers takes many forms. Formal and informal learning communities can act as powerful mechanisms for ongoing teacher growth and development (Desimone, 2009). As a result of the evolving understanding of professional learning, 
Desimone argued for a need to shift from a focus on discrete activities such as workshops towards a broad-based view of professional development that is described in terms of certain well-identified features, and found that it is these features that make professional development effective regardless of the professional development format or model utilized. Desimone's (2009) work on the professional development research body identified the following features that are critical to increasing teacher knowledge, skills, and confidence: 1) content focus, 2) active learning, 3) coherence, 4) duration, 5) collective participation.

While widespread agreement regarding professional-learning features exists within the literature, studies that analyze how professional learning features effect teachers of STEM are missing within the research body. A review of the related studies reveals that STEM is characterized by an experimental or "grassroots" feel (Shane, 2014, p. vii). The benefits of STEM for students are well recognized; however, there is little consistency or consensus regarding the STEM professional learning approach or approaches that provide the greatest benefit to teachers of STEM (Bybee, 2013).

Opportunities for teachers to receive targeted, effective, ongoing professional learning in the area of STEM provide probable benefits for teachers, schools, and most importantly for students (Avery \& Reese, 2013; Bybee, 2013; Nadelson, 2015; van Driel, et al., 2001). Because STEM represents an area in which elementary teachers are traditionally not confident, further studies on the features of effective professional learning that impact teacher confidence are needed (Kazempour, 2014). Some studies that investigated the effects of short-term STEM workshops and follow-up training were identified; however, few studies analyzed the features of multi-year STEM initiatives and how those features effected teacher efficacy over time (Bybee, 2013, Sanholtz \& Ringstaff, 2016).

Yager (2015) pointed out that "even STEM experts may have wrong ideas regarding efforts to promote STEM" and called for engaging "the most successful teachers in understanding the meaning of STEM as reform and how it should affect changes in teaching, learning, and student preparation for the future" (p. xiii). This study followed Yager's (2015) recommendation by researching successful STEM teachers' teaching in accomplished school organizations in order to identify specific features of professional learning that may have influenced their STEM instruction. Research into the features of professional learning that effective teachers of STEM perceived as important was likely to provide instructional leaders and professional learning providers with data on which to base decisions in planning, designing, and implementing STEM professional learning.

\section{Purpose}

The central purpose of this study was to determine the features of professional learning that influence teacher self-efficacy as perceived by teachers of STEM. The study sought further to discover the relative influence of specific features of professional learning on teacher self-efficacy/attitudes towards STEM. Finally, the researchers sought to determine other factors contributing to self-efficacy. This study focused on elementary teachers in grades 1 
through 5 who were responsible for teaching math and science.

\section{Method}

Because the purpose of the study was to understand how features of professional learning influence teachers' efficacy in teaching STEM, a grounded theory methodology was utilized. The complexities of STEM instruction as well as the multiple formats and models of professional learning participant teachers received over time at their schools made grounded theory an appropriate method for answering the research questions and gaining insight into the broad range of complex factors involved. The research questions focused on the key features of effective professional learning and their influence on teacher efficacy towards STEM.

The grounded theory in this study reflected experiences of elementary teachers in grades 1-5 who were identified as effective and confident in implementing STEM curriculum. The researchers sought to identify the features of professional learning that those teachers identified as important in shaping their self-efficacy in teaching STEM while involved in a multi-year STEM endeavor.

\subsection{Participants}

The study employed a purposeful sampling of teachers of STEM. Participants were limited to elementary teachers in grades 1-5 in public school systems who were involved in STEM initiatives for at least three years. STEM coaches or building level administrators, who had observed teachers implementing STEM curriculum over time, nominated potential teacher research subjects. The school leaders nominated participant teachers based on their observed confidence and effectiveness in implementing STEM. The researchers selected school districts that were distinguished in STEM education by recognition, grants, and/or awards. Likewise, the researchers selected schools within the districts that have STEM teachers with the desired years of STEM experience.

Teachers participated in structured in-depth interviews conducted by the researchers according to pre-established protocols. Interviews were audio recorded and transcribed after interview completion. Interviews were conducted with the assumption that participant teachers had the ability to recall and accurately report their professional learning experiences over the multi-year period of their participation in the STEM initiative.

\subsection{Data Analysis}

In order to determine the features of professional learning that influenced teacher self-efficacy as perceived by teachers of STEM, the researchers determined the broad themes that emerged through coding data from the transcripts. Raw data were grouped together to form indicators -segments of information that are collected from the different individuals in study. These indicators were in turn grouped into codes. This systematic coding process insured research findings were grounded in the collected data. Analysis of interview data followed established qualitative research procedures of open coding, axial coding, and 
selective coding. Open coding was used to form initial categories of information by segmenting the information from the interview transcripts. Similarities in key sentences, sentence segments, or phrases that reflect key ideas were identified and sorted. These similar ideas formed key categories and sub-categories. Axial coding followed open coding, during which selected open coding categories were explored in relation to the other open coding categories to determine the interrelationship among categories. In the third phase of coding, selective coding was utilized to develop a theory regarding teacher professional learning features and teacher self-efficacy in teaching STEM.

In order to determine the features of professional learning that influenced teacher self-efficacy as perceived by teachers of STEM, the researchers determined the broad themes that emerged through coding data from the transcripts. Next, the researchers provided a deeper analysis of these broad themes using the conceptual lens of each core feature, considering the relationship and relative influence of each. Finally, the researchers provide other significant factors that emerged contributing to self-efficacy that were noted by teachers. The interviews provided insight into the professional learning of STEM teachers and how these opportunities contributed to their efficacy towards STEM.

\section{Results Related to Themes}

Six broad themes emerged from interview transcript coding relating to teacher self-efficacy in STEM professional learning: a) student focus, b) STEM learning continuum, c) networking, d) expertise, e) culture, and f) turnaround training.

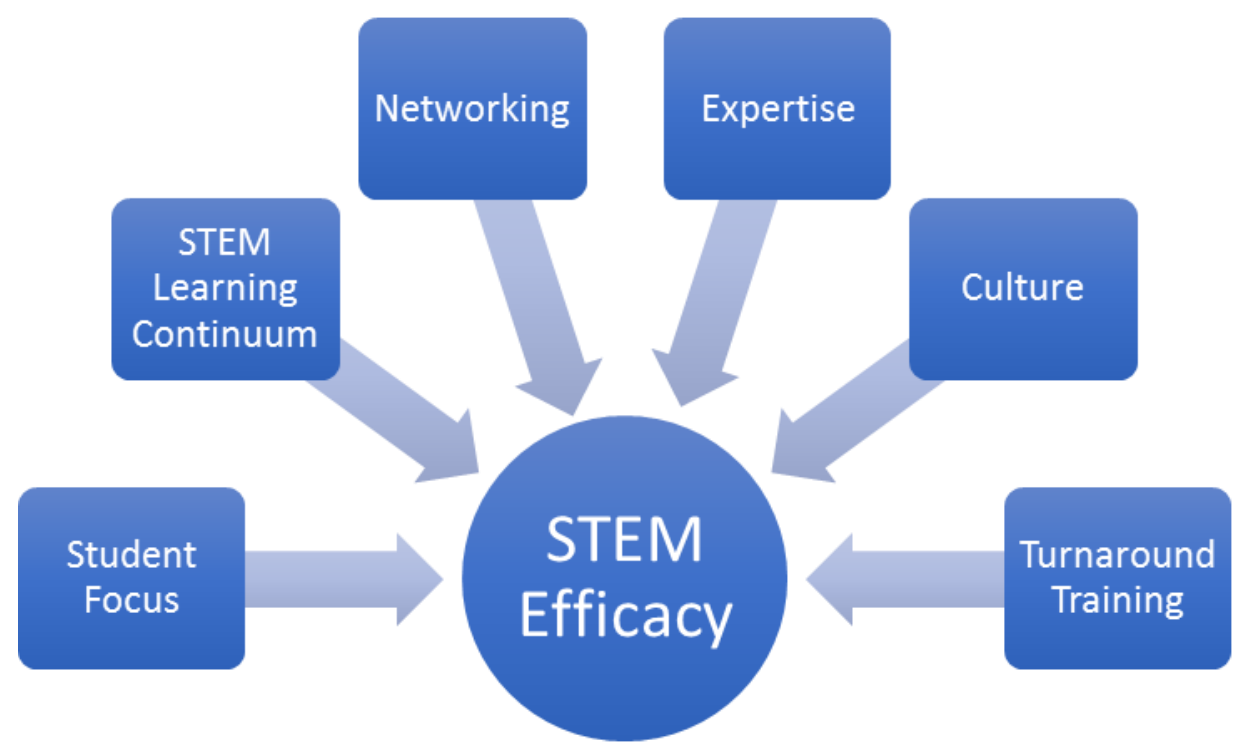

Figure 1. Emergent Themes Contributing to STEM Efficacy

A focus on students emerged as a major theme in all of the interviews, indicating that there is evidence that the elementary STEM teachers possessed strong beliefs that integrated STEM provided the most effective learning approach for their students. This theme was often linked 
with the teachers' reason for initially experimenting with STEM professional learning and instruction.

A second major theme that emerged was the concept of a STEM teacher learning continuum. Several teachers conceived of a professional learning continuum ranging from the least experienced to most experienced STEM teachers. Participant teachers favored professional learning models in which teachers could find relevant professional learning activities regardless of where they were on the STEM learning continuum or their level of experience in STEM.

The third major theme was networking. Most of the teachers had taken part in networking with STEM colleagues beyond their school. Informal groups were mentioned a total of 36 times. Multiple teachers indicated that the available resources related to STEM are still limited and found that "reaching out" through chats, Twitter, conferences, and online sessions to find those "connections" was important. Four of the seven teachers spoke about using social media. The researchers noticed that four teachers who were younger in age mentioned using social media, while the three older teachers did not mention social media.

Expertise emerged as a theme related to teacher learning. School building experts were mentioned by each of the seven participants - a total of 26 times. This included both STEM teachers seeking expertise from outside individuals/groups and schools promoting teacher expertise within the school building. Teachers mentioned growth in expertise through national conferences and by completing state sponsored STEM Laureate programs.

The theme of culture emerged by combining a number of related reoccurring codes that emerged. This included culture in the school and culture among teams of teachers. The importance of teacher perceptions of a supportive culture provided by principals, assistant principals, and other school administrators was frequently mentioned in interviews. The researchers noted that administrative support was frequently mentioned first by the STEM teachers. The large number of STEM conferences mentioned by teachers was significant.

The theme of turnaround training or training fellow teachers emerged from the data, indicating that the model has important implications for STEM professional learning. All seven participants mentioned a turnaround training model for a total of 33 times. Teachers felt it was important to go to national, regional, state, or local training to gain additional STEM information, tools, or techniques and then bring those resources back to the school level to plan and provide turnaround training for the rest of the teachers in the school.

\section{Results Related to Desimone Framework}

Desimone (2009) identified a set of key professional learning features that are significant to increasing teacher knowledge, skills, and confidence. Desimone noted that there was a great degree of overlap of various professional models and argued that it was more precise to evaluate the effectiveness of professional development by a set of common features that are nearly universal in the body of literature. The core features were present in the data collected 


\section{Mll Macrothink}

during the interviews. The table below shows the total frequency counts for each core feature.

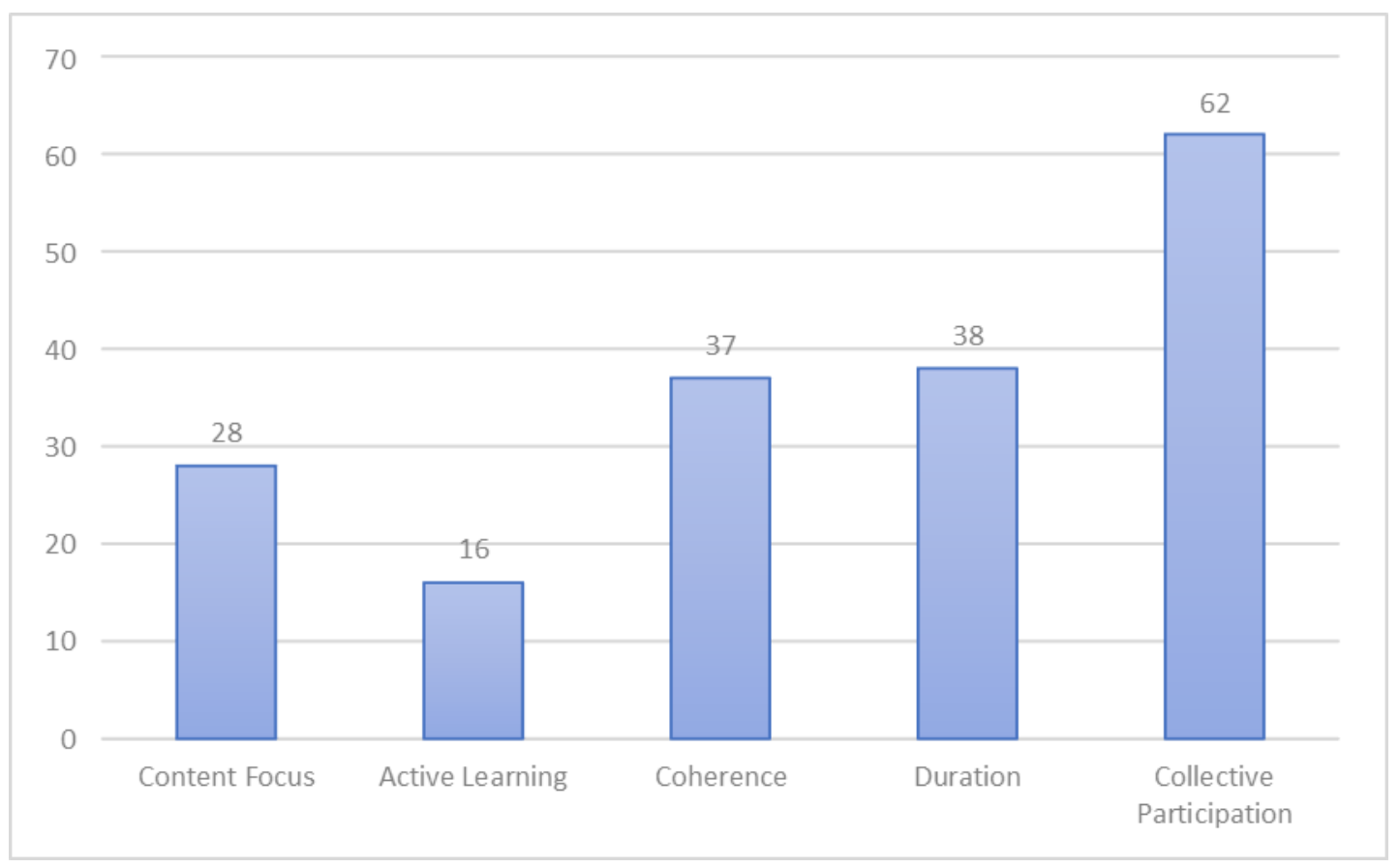

Figure 2. Core Feature Frequency

\subsection{Content Focus}

The researchers found that much of the effective professional learning identified by teachers was characterized by content focus. Content focus was identified as a feature of professional development in all seven of the interviews. Content focus was mentioned with an average frequency of 3.14 times per interview and three participants mentioned the feature of content focus five times each. Content focus was often related to course of study standards. Teachers described professional learning opportunities in which they collaborated with other teachers to design STEM lessons or units that incorporated learning objectives and standards from the course of study. Teachers described beneficial learning opportunities in which teams of teachers worked on integrating new content or tools into STEM curriculum. Teachers expressed a preference for professional learning activities that were content focused and curriculum driven. They viewed content-focused professional learning opportunities as confidence building for teachers. Participant teachers believed that content focused learning opportunities were more practical for teachers.

\subsection{Active Learning}

The core feature of active learning was described less frequently in interviews than any of the other core features. Active learning was mentioned 16 total times in the seven interviews. Two of the teachers did not mention active learning as a professional learning feature in their interviews. While this averages about 2.3 mentions per interview, this statistic is misleading due to an outlier, who mentioned active learning nine times in her interview. The researchers noted that active learning was often described as a key component of STEM student learning 
in their classroom, but the researchers did not include these data in the analysis because the references to active learning was related to classroom practices with students rather than features of teacher learning and therefore fell outside the scope of this study. While mentioned with less frequency, teachers expressed a preference for learning in which they actually learned about STEM in an active manner.

\subsection{Coherence}

According to Desimone (2009), coherence is present as a professional learning feature when teacher learning is consistent with teachers' knowledge and beliefs. Coherence was mentioned a total of 37 times in the interviews -an average of over five times per interview. All seven STEM teachers spoke about professional learning related to coherence. The researchers found that coherence was related to the emergent theme of student focus, which was identified by teachers as a reason for teachers initially implementing STEM. The core feature of coherence was strongly related to the emergent theme of a STEM learning continuum, also. Participants favored professional models that provided for choice and flexibility -allowing teachers to share expertise or gain confidence in an area, topic, or tool where they were in need of additional understanding.

\subsection{Duration}

Desimone (2009) noted that professional development had to be of sufficient duration in order to produce intellectual and pedagogical change in teaching practices. The core feature of duration was mentioned 38 total times in the seven interviews. All seven participant teachers made reference to the duration of professional learning. Desimone (2009) stated that there is no definitive effective threshold for the span of time or total number of hours spent on the learning topic. In six interviews referencing duration, the teachers were referring to ongoing school-based professional learning efforts such as team meetings or professional learning community (PLC) meetings.

Another way in which duration was present within the interviews was in references made to STEM learning experiences over time. Multiple teachers commented regarding that it had taken them years to learn to teach STEM.

\subsection{Collective Participation}

The professional learning core feature of collective participation was identified a total of 62 times -the highest frequency of any of the core features. Collective participation was mentioned an average of 8.86 times per interview. Statements underscored the importance of having teachers working together on STEM learning in teams. These teams might be either formal or informal.

While Desimone's definition of collective participation was limited to teachers from the same school, grade, or department, all seven of the teachers participating in this study were collaborating with other partners outside of their schools. These partnerships included other educators, STEM experts, STEM professionals, higher-education partners, businesses, and community partners. Collaboration was achieved in a number of different formats including 
site visits, face-to-face lessons, as well as using virtual tools such as video-conferences and social media tools. The emergent theme of networking was strongly related to the feature of collective participation.

\subsection{Other Factors: Administrative Support}

Teachers cited support and understanding from school administrators as a key to STEM effectiveness. All seven participants mentioned administrative support, and in several instances administrative support was the first factor mentioned when teachers were asked what had given them the confidence to teach STEM. This theme of administrative support was linked to risk-taking and experimenting with STEM in the classroom without a fear of failure.

\section{Discussion}

The teachers participating in this study exhibited great confidence and self-efficacy in describing their STEM learning and teaching experiences. The teacher participants in the study were able to effectively communicate their experiences in learning STEM and to identify important factors in implementing STEM effectively in the elementary classroom.

\subsection{Variety of Professional Learning Activities}

The researchers found that the ability of the participants to engage in a high volume of diverse professional learning activities over time contributed to their STEM expertise and self-efficacy. This finding supports the findings of other researchers that teachers require a significant volume of professional learning to become confident teachers of STEM in the classroom (Bybee, 2013; van Driel, et al., 2001; Nadelson, et al., 2013). The scope of the professional learning of teachers in the study was both wide and deep, including STEM conferences, informal study groups, social media groups, and professional learning communities. Some of the teachers sought add-on STEM certifications. The professional learning included both formal and informal activities. The researchers found this wide range of learning was key to teacher self-efficacy.

It appears the teachers of STEM achieved a high-level of self-efficacy because they were resourceful in networking with the goal of pursuing of greater knowledge. A lack of valuable STEM resources at the local level is often noted in the body of literature (Bybee, 2013). The STEM teachers in this study networked at conferences, on social media, and with teachers within their schools as well as at other schools. They participated in book studies and networked on Twitter and Facebook. Participants pursued a wide range of learning activities as evidenced in the data collected for this study. It is likely that teachers broaden their network after discovering that STEM resources, expertise, and STEM training was available beyond the local level.

\subsection{Development of Expertise}

Expertise emerged in the research data as important in teaching STEM. Based on interview 
content and context, it appears that each of the seven teachers participating in the study were key leaders in the STEM area within their school. The large volume of diverse professional learning they engaged in contributed to their expertise and confidence in STEM. Because of the high levels of confidence and knowledge these teachers exhibited about STEM, it seems likely that other teachers in their building would consider the seven participating teachers to be resident STEM experts. This study suggests that in order for schools to realize widespread STEM implementation in the organizations, it is important to establish a strong core of STEM "true believers" who are eager and willing to maintain a focus on STEM and who can provide a model and a guide for less confident teachers. Having a core of STEM expertise within the school is likely to benefit other elementary teachers as they implement STEM.

\subsection{Culture of Risk and Support}

School culture emerged as a significant theme underlying efforts to increase STEM implementation. All the teachers stated that STEM implementation requires experimentation and risk-taking. Even highly-confident teacher experts stated that their STEM lessons are routinely chaotic, imperfect, or experience failures. It is unlikely that teachers will take the inherent risks associated in their classroom practices unless they perceive a supportive and low-risk school culture. Other studies have emphasized the importance of teachers experiencing active learning and risk-taking (Slavit, et al., 2016).

The researchers found that the support of principals and other building level administrators is key in establishing this culture that encourages innovation and experimentation. Principals who require strict adherence to curriculum and pacing guides may not provide teachers the flexibility to integrate standards (Sanholtz and Ringstaff, 2016). All the study participants mentioned their school administration and described those administrators as supportive and as key to their STEM learning.

\subsection{Turnaround Training}

Turnaround training emerged as a central concept in the research. All seven of the participant teachers mentioned attending STEM-related conferences and then bringing that STEM training back to share with the school staff. Turnaround training might be of particular value in the STEM field due to the limited availability of STEM resources locally. Schools that find it impractical to send large numbers of teachers to STEM conferences, may choose the more practical alternative of sending small, carefully selected teams of teachers to national conferences, who in turn provide turnaround training at the school level. In essence, sending small teams of teachers may have represented a more feasible way to provide learning opportunities for the school staff. Teachers representing their schools at STEM conferences felt increased confidence to share STEM learning with the staff.

\section{Conclusions}

The research provided insight into how to best provide professional learning for STEM teachers. The learning experiences of STEM teachers have potential application for other 
content areas in teaching.

\subsection{Begin with a Focus on Student Benefits \& Revisit this Focus}

School leaders and other educators seeking to implement STEM in elementary classrooms would be prudent to focus on the benefits of a STEM approach on students prior to embarking on STEM initiatives. The STEM teachers in the study shared beliefs that integrated STEM approaches provided more benefits to students than traditional teaching methods/curriculum. These beliefs were frequently correlated with teachers' reasons for embarking in STEM learning activities. The results imply that teachers need to fully comprehend and internalize reasons why they should expend the significant energy, time, and resources needed to teach STEM effectively. This is understandable given the limited time and resources available to most teachers. If school leaders dive into STEM professional learning and neglect spending time in discussing benefits to students and building a common set of beliefs, minimal compliance from teachers is likely to be the result, and it seems unlikely that students will receive the benefits of effective integrated STEM instruction in the classroom.

\subsection{Establish a Supportive School Culture that Encourages Risk-Taking}

STEM teachers need to feel that the school culture encourages experimentation and risk-taking. Because STEM lessons are more likely to go poorly or fail, teachers are unlikely to risk STEM unless they perceive that principals and other administrators will be supportive. Several of the teachers spoke about a "no-fear" mindset as being critically important. Without a supportive culture, teachers are more likely to revert back to traditional methods that they perceive to be safer.

\subsection{Form a Core of Expertise}

The depth of STEM expertise exhibited by teachers in the study was remarkable. Elementary teachers are often responsible for teaching multiple subjects each school day. Time for planning and organizing materials are in short supply and there are myriads of things that compete for the attention of teachers each day. The teachers in the study showed great resourcefulness in pursuing STEM training that they could share with other teachers in their building. This core of STEM expertise in the school organization is valuable because it can function in many supportive roles; providing training, mentoring, advancing the STEM agenda, and serving as a model for other teachers. If STEM is only being advocated by principals and other instructional leaders, it is unlikely to be embraced by teachers or be integrated in the school.

\subsection{Establish Opportunities for Collaboration}

Of all the core features, collective participation emerged as the most significant. Teachers of STEM need mutual support because of the high-demands of teaching STEM. Collaboration proved important in building a cohesive culture of STEM professional learning. The findings showed that self-efficacy is influenced by working with others on STEM learning. Face to face collaboration as well as virtual collaboration with social media allowed teachers to grow 
as STEM teachers.

\subsection{Plan Ongoing Professional Learning that Incorporates Each of the 5 Core Features}

The researchers found that each the core features benefits teachers of STEM. It is likely that these benefits are more important in STEM professional learning than in other topics of teacher learning. This is because of the nature of STEM itself.

\section{Recommendations for Further Study}

Larger scale studies are recommended. Larger scale studies would have greater reliability and would be useful in confirming results of this study and generalizing those results to teachers seeking to learn about STEM. Longitudinal studies with experimental designs would allow the study of teachers of STEM over time and would add to the findings of this study. Longitudinal studies would be useful in determining the sustainability of STEM professional learning over the long term. This study used one source of qualitative data. Mixed methods studies utilizing both qualitative and quantitative methods that factor multiple data sources would enhance understanding of the findings.

\section{Summary}

In summary, the findings of the current study imply that STEM professional learning is complex and challenging for teachers. The researchers conclude that while there existed a high degree of similarity in the learning experiences of STEM teachers who were participants in the study, this fact should in no way convince readers of this study that STEM proficiency and confidence can be achieved by following a simple set formula. STEM proficiency and confidence were achieved by the teachers in this study through their own resourcefulness, hard work, and time. Following the recommendations of this study are likely to provide teachers with the support they need in achieving greater learning and confidence, in turn producing beneficial results for their students. Educators pursuing STEM benefit from broad-based support and efficient, well-designed professional learning activities over a long duration in order to become confident and effective teachers of STEM.

\section{References}

Avery, Z., \& Reeve, E. (2013). Developing effective STEM professional development

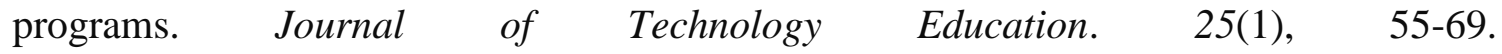
https://doi.org/10.21061/jte.v25i1.a.4

Bybee, R. W. (2013). The case for STEM education. Arlington, VA: NSTA Press. https://doi.org/10.2505/9781936959259

DeJarnette, N. K. (2012). American's children: Providing early exposure to STEM (science, technology, engineering, and math) initiatives. Education, 133, (1), 77-168. 


\section{Macrothink}

International Journal of Education ISSN 1948-5476

Desimone, L. (2009). Improving impact studies of teachers' professional development: Toward better conceptualizations and measures. Educational Researcher, 3(38), 181-199. https://doi.org/10.3102/0013189x08331140

Galosy, J. A., \& Gillespie, N. M. (2013). Community, inquiry, leadership: Exploring early career opportunities that support STEM teacher growth and sustainability. The Clearing House: A Journal of Educational Strategies, Issues and Ideas, 86(6), 207-215. https://doi.org/10.1080/00098655.2013.826485

Herscbach, D. (2011). The STEM initiative: Constraints and challenges. Journal of STEM Teacher Education, 48(1), 97-122.

Kim C., Kim D., Yuan J., Hill R. B., Doshi P., \& Thai C.N., (2015). Robotics to promote elementary education pre-service teachers' STEM: Engagement, learning \& teaching, Computers \& Education. https://doi.org/10.1016/j.compedu.2015.08.005

Lederman, N. G., \& Lederman, J. S. (2013). Is it STEM or "S \& M" that we truly love?, Journal of Science Education, 24(8), 1237-1240. https://doi.org/10.1007/s10972-013-9370-z

Lehman, J. D., Kim, W., \& Harris, C. (2014). Collaborations in a community of practice: Working to integrate engineering design in elementary science education. Journal of STEM Education, 15(3), 21-28.

Maltese, A. V., \& Tai, R. H. (2010). Eyeballs in the fridge: Sources of early interest in science. International Journal of Science Education, 32(5), 669-685. https://doi.org/10.1080/09500690902792385

Mobley, M. C. (2015). Development of the SETIS Instrument to measure teacher's self-efficacy to teach science in an integrated STEM framework. Doctoral dissertation). Retrieved from http://Turner.tennessee.edu/cgi/viewcontent.cgi?article=4700\&context=utk_graddiss

Nadelson, L. (2015). Who is doing the engineering, the student or the teacher? The development and use of a rubric to categorize level of design for the elementary classroom. Journal of Technology Education, 26(2), 22-45. https://doi.org/10.21061/jte.v26i2.a.2

Nadelson, L. S., Callahan, J., Pyke, P., Hay, A., Dance, M., \& Pfeister, J. (2013). Teacher STEM perception and preparation: Inquiry-based STEM professional development for elementary teachers. The Journal of Educational Research, 106(2), 157-168. https://doi.org/10.1080/00220671.2012.667014

National Academy of Science, Engineering, and Medicine (2015). Science teachers learning: Enhancing opportunities, creating supportive contexts. Washington DC: The National Academies Press. https://doi.org/10.17226/21836 
National Science Teachers Association (2002). NSTA position statement: Early childhood science education. Arlington, VA: NSTA. Retrieved from http://www.nsta.org/about/positions/earlychildhood.aspx

NGSS Lead States. (2013). Next Generation Science Standards: For states by states. Washington, DC: The National Academies Press. https://doi.org/10.17226/18290

Organization for Economic Cooperation and Development (2012). Program for International Student Assessment (PISA). Retrieved April 20, 2016 from: http://www.oecd.org/pisa/keyfindings/PISA-2012-results-US.pdf https://doi.org/10.1787/9789264167872-2-en

President's Council of Advisors on Science and Technology. (2011). Prepare and inspire: K-12 education in science, technology, engineering, and math (STEM) for America's future. $\quad$ Retrieved from http://www.whitehouse.gov/sites/default/files/microsites/ostp/pcast-stem-ed-final.pdf

Sandholtz, J. H., \& Ringstaff, C. (2016). The influence of contextual factors on the sustainability of professional development outcomes. Journal of Science Teacher Education, 27(2), 205-226. https://doi.org/10.1007/s10972-016-9451-x

Shane, P. (2014). Foreword. In Wojnowski, B. S., \& Pea, C. H. (Eds.). Models and approaches to STEM professional development. (vii-viii). Arlington, VA. NSTA Press. https://doi.org/10.2505/9781936137350

Slavit, D., Nelson, T. H., \& Lesseig, K. (2016). The teachers' role in developing, opening, and nurturing an inclusive STEM-focused school. International Journal of STEM Education, 3(1), 7. https://doi.org/10.1186/s40594-016-0040-5

van Driel, J. H., Beijaard, D., \& Verloop, N. (2001). Professional development and reform in science education: The role of teachers' practical knowledge. Journal of research in science teaching, 38(2), 137-158. https://doi.org/10.1002/1098-2736(200102)38:2<137::aid-tea1001>3.0.co;2-u

Yager, R. E. (2015). The role of exploration in the classroom (STEM). Society, 52(3), 210-218. https://doi.org/10.1007/s12115-015-9890-6

\section{Copyright Disclaimer}

Copyright for this article is retained by the author(s), with first publication rights granted to the journal.

This is an open-access article distributed under the terms and conditions of the Creative Commons Attribution license (http://creativecommons.org/licenses/by/3.0/). 